\title{
Evaluation of Patients with Nasal Foreign Bodies
}

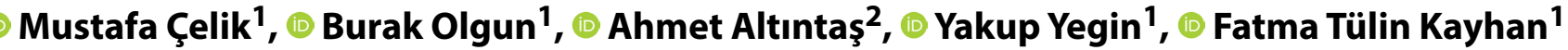 \\ ${ }^{1}$ Department of Otorhinolaryngology, Bakırkoy Dr. Sadi Konuk Training and Research Hospital, Istanbul, Turkey \\ ${ }^{2}$ Department of Otorhinolaryngology, Fatih Medical Park Hospital, Istanbul, Turkey
}

\begin{abstract}
Introduction: To evaluate the demographic data and treatment methods for patients with nasal foreign bodies and properties of foreign bodies.

Methods: In total, 243 patients (138 female; 105 male; mean age, 2.78土1.33 years; range, 1-8 years) who were diagnosed with nasal foreign bodies were included in the study. All patient records were evaluated in terms of age, sex, type and color of foreign bodies, side of presentation, and treatment protocols.

Results: Foreign bodies were detected in the left nasal cavity in 86 patients (35.4\%), right nasal cavity in 155 (63.8\%), and bilaterally in 2 (0.8\%). The most common nasal foreign bodies were beads in 78 patients (32.1\%), plant species in 67 (27.6\%), and paper-sponge particles in 34 (14\%). The most common colors of the foreign bodies were blue and brown in males and red and white in females. Fourteen (5.8\%) patients required general anesthesia for the extraction of the foreign body in an operating room.

Discussion and Conclusion: Nasal foreign bodies are a common emergency in the field of otorhinolaryngology. It is not known whether the properties of foreign bodies affect children's ability to nudge foreign objects. Further studies with greater number of patients are needed on this topic.

Keywords: Bead; foreign body; nasal; red.
\end{abstract}

$\mathrm{N}$ asal foreign bodies are very frequently seen among pediatric emergencies and constitute approximately $0.1 \%$ of all pediatric emergencies ${ }^{[1,2]}$. Among ear, nose, and throat (ENT) emergencies, the detection of a nasal foreign body is very frequently encountered. ENT foreign bodies have been reported to rank after external ear canal foreign bodies ${ }^{[3]}$. Learning by experience plays a key role during the developmental stages in children. Most children have a tendency to nudge every foreign body they find and insert it into their mouth, nose, and ears after they achieve hand coordination. Although the characteristics of foreign bodies are not very important, children may nudge every foreign body, mainly pieces of bread, cotton, paper, erasers, corns, plant beads, plastic substances, and living bodies into their nose ${ }^{[4-8]}$.Most nasal foreign body cases are seen in children aged between 1 and 3 years. Although various information has been reported about the dominant sex, it is more frequently reported among male children ${ }^{[7-10]}$. Çetinkaya et al. ${ }^{[11]}$ performed a study with 1875 cases and indicated that $52.9 \%$ of the cases who inserted foreign bodies through their nostrils were male. Yaroko et al. ${ }^{[12]}$ performed a study on 43 pediatric cases and reported that most children who inserted foreign bodies into their noses were male (60.5\%). Similarly, Abou-Elfadl et al. ${ }^{[13]}$ performed a study with 260 pediatric cases and reported that more than half of the children (58.8\%) who inserted foreign bodies into their noses were male.

Correspondence (iletişim): Mustafa Çelik, M.D. Department of Otorhinolaryngology, Bakırkoy Dr. Sadi Konuk Training and Research Hospital, Istanbul, Turkey

Phone (Telefon): +90 5335976636 E-mail (E-posta): dr.mcelik@yahoo.com

Submitted Date (Başvuru Tarihi): 26.12.2017 Accepted Date (Kabul Tarihi): 02.02.2018

Copyright 2018 Haydarpaşa Numune Medical Journal

This is an open access article under the CC BY-NC license (http://creativecommons.org/licenses/by-nc/4.0/). 
Foreign bodies in the nasal cavity may be detected by physicians using anterior rhinoscopy, flexible nasopharyngoscopy, or rigid nasal endoscopy. However, nasal mucosal edema or granulation tissue formation due to the retention of the foreign body for a long time in the nasal cavity may prevent its detection. In this condition, the use of nasal decongestants before physical and instrumental examination will facilitate the examination ${ }^{[2,3]}$. A gold standard method for the removal of foreign bodies is not currently available; the treatment method may be determined based on the patient's age and compliance and physician's discretion. In the literature, approximately 20 different foreign body extraction methods have been defined. Each method has its own advantages and disadvantages ${ }^{[14-19]}$.

In this study, demographic characteristics of the patients and nature of the extracted foreign bodies were evaluated.

\section{Materials and Methods}

This retrospective clinical study was performed between January 2012 and January 2016 in the otorhinolaryngology clinic of our hospital and included 243 patients treated for foreign bodies in their nasal cavities (138 female and 105 male; mean age, $2.78 \pm 1.33$ years; range, $1-8$ years). The study was approved by the Ethics Committee of the same hospital (decision no: 2016/191). The study was performed in compliance with the guidelines of the Helsinki Declaration Principles of Good Clinical Practices. Demographic information of the patients was obtained after screening the files in the hospital registration system. Files of all the patients were evaluated for age, sex, type of the foreign body, laterality of the foreign body, and treatment applied.

\section{Statistical Analysis}

For statistical analyses, Number Cruncher Statistical System (NCSS) 2007 (Kaysville, Utah, USA) was used. The study data were evaluated using descriptive statistical methods, such as the mean, standard deviation, median, frequency, rate, and minimum and maximum values. For the evaluation of qualitative data, the Fisher-Freeman-Halton test was used.

\section{Results}

Foreign bodies were detected in the right $(n=86 ; 35.4 \%)$, left $(n=155 ; 63.8 \%)$, and both $(n=2 ; 0.8 \%)$ nasal cavities. Various types of foreign bodies were detected, including beads ( $n=78 ; 32.1 \%)$, plant species ( $n=67 ; 27.6 \%)$, pieces of paper and sponge $(n=34 ; 14.0 \%)$, toys $(n=26 ; 10.7 \%)$, plastic objects ( $n=7 ; 2.9 \%)$, alkaline batteries $(n=12 ; 4.9 \%)$, and metal objects ( $n=19 ; 7.8 \%$; Fig. 1). The colors of the ob- jects were white $(n=66 ; 27.2 \%)$, gray $(n=39 ; 16.0 \%)$, yellow $(n=38 ; 15.6 \%)$, red $(n=28 ; 11.5 \%)$, black $(n=21 ; 8.6 \%)$, blue $(n=16 ; 6.6 \%)$, green $(n=14 ; 5.8 \%)$, brown $(n=11 ; 4.5 \%)$, and pink ( $n=10 ; 4.1 \%$; Fig. 2). The cases included in the study were referred either to the ENT outpatient clinic on an ambulatory basis ( $n=22 ; 9.1 \%)$ or from an emergency clinic to us $(n=221 ; 90.9 \%)$. Foreign bodies were removed in the operating room under general anesthesia $(n=14 ; 5.8 \%)$ or using a curette, aspirator, and alligator clamps in a polyclinic. The distribution colors of the foreign bodies according to age groups are shown in Table 1, whereas distribution of the types of foreign bodies is summarized in Table 2. A statistically significant difference was found between the colors of foreign bodies according to patients' sex $(p<0.01)$. Male cases nudged blue and brown, whereas female cases nudged red and white foreign bodies into their nasal cavities $(p<0.001 ;$ Table 3$)$.

\section{Discussion}

In previous studies, children were reported to insert foreign bodies most frequently through their right nostrils, which was related to children mostly using their right hands [19${ }^{22]}$. Generally, nasal foreign bodies are seen at only one side

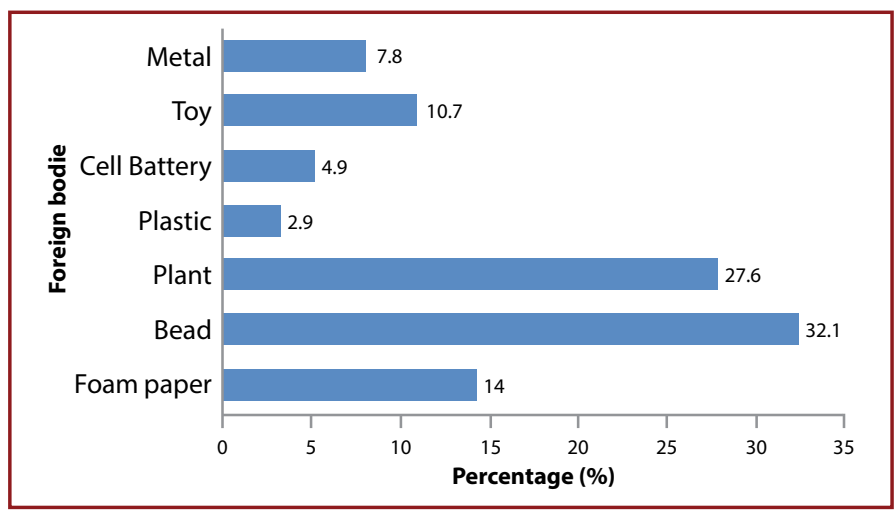

Figure 1. Distribution of foreign bodies according to their type.

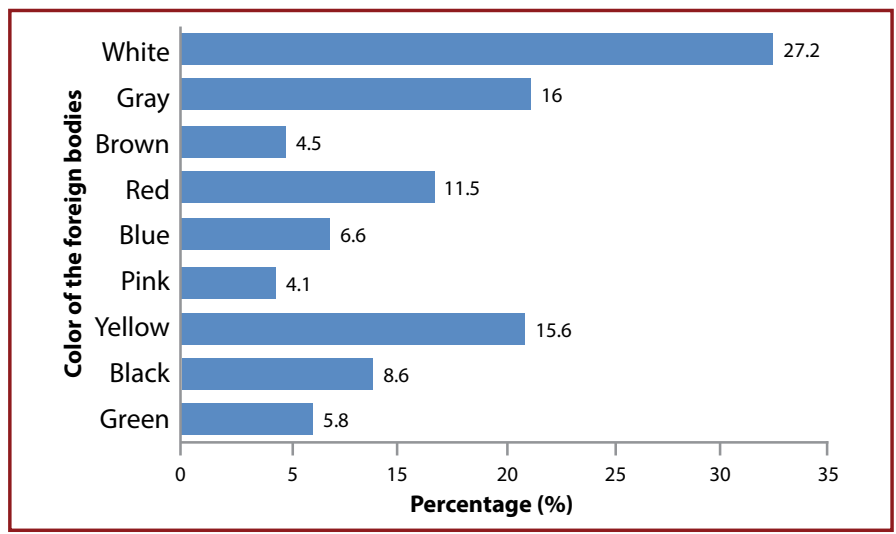

Figure 2. Distribution of foreign bodies according to their color. 
of the nose and rarely in both the nasal cavities. Yaroko et al. ${ }^{[12]}$ evaluated patients who inserted foreign bodies into their nasal cavities and detected foreign bodies mostly in the right (58.14\%) and less frequently in the left (39.53\%) and both sides (2.33\%). In this study, in line with the literature, the children most frequently inserted foreign bodies through their right nostrils (63.8\%).

Foreign bodies inserted into nasal cavities usually do not cause pain. They may remain in the nasal cavity without leading to any symptoms. Nasal obstruction and foul smell from nostrils may herald the presence of a foreign body in the nasal cavity. In this case, physician should primarily speculate the presence of a foreign body in the nasal cavity and examine accordingly. In children, unilateral purulent nasal discharge with a foul smell and unilateral vestibulitis have a considerable diagnostic significance. Yaroko et al. ${ }^{[12]}$ performed a study with 43 pediatric cases and reported that most cases were asymptomatic, and that foreign bodies were accidentally detected. Chiun et al. ${ }^{[18]}$ reported that most patients (75\%) admitted to emergency services claimed that they had inserted a foreign body into their nasal cavity. Abou-Elfadl et al. ${ }^{[13]}$ performed a study with 260 pediatric cases and reported that $76.9 \%$ of the cases claimed that they or their families inserted a foreign body into their nasal cavity. The diagnosis of foreign bodies which are not noticed by the patients or their families is delayed, and the foreign body may remain in the nasal cavity for a long period. Yaroko et al. ${ }^{[12]}$ reported that more than half of the children who inserted a foreign body into their nasal cavity did not seek medical help within the first $24 \mathrm{~h}$ and more frequently applied within the first week.

Nasal foreign bodies may be inanimate objects or living creatures. In the literature, most frequently seen nasal foreign bodies have shown different incidence rates. Most frequently detected inanimate foreign objects include beads $(9 \%-31 \%)$, pieces of plastic toys $(9 \%-18 \%)$, erasers $(7 \%-23 \%)$, paper $(4 \%-7 \%)$, cotton $(2 \%-10 \%)$, and pebbles or sand particles (7\%-14\%).(8-13, 16-19) Living for-

Table 1. Distribution of colors of the foreign bodies according to age groups

\begin{tabular}{|c|c|c|c|c|c|}
\hline & \multicolumn{5}{|c|}{ Age groups } \\
\hline & $\begin{array}{c}1 \\
\text { n (\%) }\end{array}$ & $\begin{array}{c}2 \\
\text { n (\%) }\end{array}$ & $\begin{array}{c}3 \\
n(\%)\end{array}$ & $\begin{array}{c}4 \\
n(\%)\end{array}$ & $\begin{array}{c}>5 \\
\mathrm{n}(\%)\end{array}$ \\
\hline \multicolumn{6}{|c|}{ Color of the foreign bodies } \\
\hline Green & $5(13.5)$ & $4(5.0)$ & $3(4.5)$ & $2(6.1)$ & $0(0.0)$ \\
\hline Black & $3(8.1)$ & $3(3.8)$ & $4(6.1)$ & $3(9.1)$ & $8(29.6)$ \\
\hline Yellow & $4(10.8)$ & $16(20.0)$ & $7(10.6)$ & $6(18.2)$ & $5(18.5)$ \\
\hline Pink & $2(5.4)$ & $3(3.8)$ & $2(3.0)$ & $1(3.0)$ & $2(7.4)$ \\
\hline Blue & $0(0.0)$ & $4(5.0)$ & $7(10.6)$ & $5(15.2)$ & $0(0.0)$ \\
\hline Red & $8(21.6)$ & $7(8.8)$ & $9(13.6)$ & $3(9.1)$ & $1(3.7)$ \\
\hline Brown & $1(2.7)$ & $2(2.5)$ & $6(9.1)$ & $2(6.1)$ & $0(0.0)$ \\
\hline Gray & $4(10.8)$ & $11(13.8)$ & $11(16.7)$ & $6(18.2)$ & $7(25.9)$ \\
\hline White & $10(27.0)$ & $30(37.5)$ & $17(25.8)$ & $5(15.2)$ & $4(14.8)$ \\
\hline
\end{tabular}

Table 2. Distribution of the types of foreign bodies according to age groups

\begin{tabular}{|c|c|c|c|c|c|}
\hline & \multicolumn{5}{|c|}{ Age } \\
\hline & $\begin{array}{l}1 \text { year } \\
\text { n (\%) }\end{array}$ & $\begin{array}{c}2 \text { years } \\
\text { n (\%) }\end{array}$ & $\begin{array}{c}3 \text { years } \\
\text { n (\%) }\end{array}$ & $\begin{array}{c}4 \text { years } \\
\text { n (\%) }\end{array}$ & $\begin{array}{c}>5 \text { years } \\
n(\%)\end{array}$ \\
\hline \multicolumn{6}{|l|}{ Foreign bodies } \\
\hline Paper & $7(18.9)$ & $19(23.8)$ & $5(7.6)$ & $2(6.1)$ & $1(3.7)$ \\
\hline Bead & $11(29.7)$ & $14(17.5)$ & $26(39.4)$ & $18(54.5)$ & $9(33.3)$ \\
\hline Plant & $12(32.4)$ & $31(38.8)$ & $14(21.2)$ & $6(18.2)$ & $4(14.8)$ \\
\hline Plastic material & $2(5.4)$ & $2(2.5)$ & $0(0.0)$ & $0(0.0)$ & $3(11.1)$ \\
\hline Cell Battery & $3(8.1)$ & $4(5.0)$ & $2(3.0)$ & $2(6.1)$ & $1(3.7)$ \\
\hline Toy & $1(2.7)$ & $8(10.0)$ & $13(19.7)$ & $3(9.1)$ & $1(3.7)$ \\
\hline Metal & $1(2.7)$ & $2(2.5)$ & $6(9.1)$ & $2(6.1)$ & $8(29.6)$ \\
\hline
\end{tabular}


Table 3. Distribution of the colors of the foreign bodies according to patient sex

\begin{tabular}{lccc}
\hline & \multicolumn{2}{c}{ Gender } & \\
\cline { 2 - 3 } & $\begin{array}{c}\text { Female } \\
\mathbf{n}(\%)\end{array}$ & Male & \\
& & $\mathbf{a}(\%)$ & \\
\hline Color of the foreign body & & & \\
Green & $10(7.2)$ & $4(3.8)$ & \\
Black & $12(8.7)$ & $9(8.6)$ & \\
Yellow & $21(15.2)$ & $17(16.2)$ & \\
Pink & $6(4.3)$ & $4(3.8)$ & \\
Blue & $5(5.6)$ & $11(10.5)$ & $<0.001$ \\
Red & $20(14.5)$ & $8(7.6)$ & \\
Brown & $3(2.2)$ & $8(7.6)$ & \\
Gray & $21(15.2)$ & $18(17.1)$ & \\
White & $40(29.0)$ & $26(24.8)$ & \\
\hline
\end{tabular}

${ }^{\mathrm{a}}$ Fisher-Freeman-Halton Test; $\mathrm{p}<0.001$.

eign objects have been less frequently reported; these are generally seen in individuals living in poor hygienic conditions. Most frequently, ascaris larvae, ticks, and insects are encountered. ${ }^{[18]}$ Ogunleye et al. ${ }^{[15]}$ reported pieces of plants and seeds as the most frequently detected foreign bodies in their study. Yaroko et al. ${ }^{[12]}$ reported seeds, rubber particles, and cell batteries as the most frequently detected nasal foreign bodies. In this study, most frequently detected foreign bodies were beads (32.1\%), plant species (27.6\%), and pieces of paper and sponge (14.0\%).

Adequate literature is not available pertaining to the reason why children nudge foreign bodies through their nostrils; furthermore, literature about the characteristics of the foreign bodies they insert into their nasal cavities is lacking. It is not known whether shapes, consistencies, weights, and colors of the foreign bodies are effective factors for children's selection of the foreign bodies. However, various studies have indicated that children who start schooling are more interested in colored books which contribute to their enthusiasm to learn ${ }^{[23-25]}$. In the present study, colors of the foreign bodies inserted into the nasal cavities were evaluated. More frequent insertion of colored objects into nasal cavities suggested that color of the foreign body is an effective factor. Besides, a significant difference was detected between male and female children in terms of the color of the foreign body they inserted. Male children preferred blue and brown, whereas female children preferred red and white. The differences in the foreign body color according to sex remain unclear. Further studies should be conducted to decide whether this preference is purely coincidental or whether male and female children assume different meanings to different colors. Psychoanalytical studies performed on this issue will clarify this dilemma.

The requirement for radiological evaluation in cases with nasal foreign bodies is still a controversial issue. Some authors have advocated that in cases with suspected nasal foreign bodies that cannot be detected using rhinoscopy and flexible nasopharyngoscopy, radiological examination is imperative. However, a definitive indication could not be defined. Oh et al. ${ }^{[26]}$ reported that radiological imaging should be performed in poorly cooperative cases with suspected nasal foreign bodies who reject instrumental examination. In their study, they detected $4(11.4 \%)$ nasal foreign bodies on radiological examinations performed in 35 cases. They also indicated that a routine conduction of imaging studies did not provide any benefit ${ }^{[26]}$. In the detection of radiopaque objects, such as metal, cell batteries, and pebble stones, X-ray examination appears to be adequate. Since most cases are in the pediatric age group and considering the risks in their exposure to radiation, radiological examination should not be performed unless absolutely necessary. In this study, files of each case were analyzed, and we detected that one of the cases had undergone radiological examination for the detection of nasal foreign bodies.

Successful removal of foreign bodies depends on the location of the foreign body inside the nasal cavity, characteristics of the foreign body, patient's compliance, experience of the physician, presence of required equipment, and nonadhesion of the foreign body to the surrounding tissue. However, four important conditions are required for the successful removal of the foreign body from the nasal cavity $[14,15,18]$. The first prerequisite is placing the patient in a correct position. Pediatric patients should be seated in their parents' lap, with their head and body in a fixed position so as to prevent the escape of the foreign body into the nasopharynx. Incorrect positioning may cause very serious problems. Because most patients are aged $<3$ years, the critical importance of correct positioning can be justified. During the extraction of the foreign body, it may fall into the respiratory tract, leading to respiratory failure. Gandhi et al. ${ }^{27]}$ reported higher foreign body aspiration rates among pediatric patients aged 1-3 years. The second prerequisite is the availability of an optic system, which would enable adequate evaluation of the nasal cavities. In ENT clinics, headlights appear to be ideal for this procedure. Light source to be used for the evaluation of the nasal cavities should allow the physician to use his/her both hands; thus, use of headlights seems to be more rational. The third prerequisite is to use a nasal speculum of adequate 
size. Nasal speculum should be used correctly so as to permit the removal of the foreign body from the nasal cavity. Speculum may restrict the extraction of bigger foreign bodies from the nostrils. The fourth prerequisite is to make the procedure less painful using nasal decongestants and analgesics. Experiencing pain may hamper the extraction process. Therefore, before extraction of the foreign body, appropriate doses of decongestants should be applied on the nasal cavity for successful extraction. However, despite achieving all the prerequisites, because of poor cooperation of the patient and the family in addition to the size and position of the foreign body, it may not be removed under polyclinic conditions; therefore, operating room setting may be required. Yaroko et al. ${ }^{[12]}$ performed a study with 43 pediatric cases and reported that foreign bodies were extracted under general anesthesia (53.49\%), in polyclinic conditions (41.86\%), or were passed spontaneously (46.5\%). Although the removal of foreign bodies from the nasal cavity under general anesthesia is helpful because it decreases complications and provides easy working conditions for the physician, the risk and complications associated with general anesthesia should be adequately considered from the patient's perspective. In our country, because of the inadequate number of operating rooms, anesthetists, and surgical teams and inability to have emergency operating room settings in every hospital, operating patients with intranasal foreign bodies is challenging. Therefore, the removal of foreign bodies is realized more frequently in outpatient clinics or emergency observation rooms. Under these conditions, patients become more agitated, and the physician faces difficulties during the procedure, thereby increasing the procedural complication rate. Trials for the extraction of the foreign body under ambulatory conditions have resulted in the aspiration of the foreign body, ensuing respiratory failure or even death. During trials of removing the foreign body in a poorly cooperative patient, if the foreign body is localized near the choana and the equipment required for emergency tracheotomy are not available, administration of general anesthesia would be more appropriate. If the consulted hospital does not have the required facilities, then the patient should be referred to a hospital having these facilities. In this study, in only 14 $(5.8 \%)$ cases, the foreign body was extracted under general anesthesia; other cases were treated under polyclinic conditions using a curette, aspirator, and alligator clamps.

Although complications are not very frequently encountered during the removal of nasal foreign bodies, nosebleed and septum perforation are mostly seen ${ }^{[12,13]}$. Septum perforation usually occurs as a result of fat necrosis caused by a chemical substance, such as cell batteries, in the septum mucosa ${ }^{[22]}$. Cylindrical cell batteries lead to severe destruction of the nasal mucosa and septum and serious complications. Septum perforation, synechia, narrowing of the nasal cavity, and collapse of the septum are among the expected complications $[6,14]$. Therefore, if chemical substances, such as cell batteries, are inserted into the nasal cavity, they should be removed without delay. Especially, for the prevention of destruction caused by cell batteries in the nasal mucosa, nasal irrigation and moistening should be used. Keeping the cases under control will enable the prevention of more serious complications before their development. In this study, during the extraction of foreign bodies, septum perforation was not detected in any case. Intranasal foreign bodies induce the growth of microorganisms that may cause serious mortal infections, such as acute sinusitis, acute otitis, periorbital cellulitis, meningitis, acute epiglottitis, diphtheria, and tetanus. If the foreign body remains in the nasal cavity for a long period, granulation tissue develops around it and may lead to rhinolitis ${ }^{[12,27]}$.

\section{Conclusion}

Foreign bodies in the nasal cavity are frequently seen among ENT emergencies. It is not known whether the characteristics of foreign bodies have any effect on their insertion into the nasal cavity. In consideration of the patient's age, general health, characteristics of foreign bodies, and resulting symptoms, foreign bodies should be removed with minimal complications by experienced ENT specialists.

Peer-review: Externally peer-reviewed.

Authorship Contributions: Concept: M.Ç., Y.Y., B.O., A.A., F.T.K.; Design: M.Ç., Y.Y., B.O., A.A., F.T.K.; Data Collection or Processing: M.Ç., Y.Y., B.O., A.A., F.T.K.; Analysis or Interpretation: M.Ç., Y.Y., B.O., A.A., F.T.K.; Literature Search: M.Ç., Y.Y., B.O., A.A., F.T.K.; Writing: M.Ç., Y.Y.

Conflict of Interest: None declared.

Financial Disclosure: The authors declared that this study received no financial support.

\section{References}

1. Taylor C, Acheson J, Coats TJ. Nasal foreign bodies in children: kissing it better. Emerg Med J 2010;27:712-3. [CrossRef]

2. Benjamin E, Harcourt J. The modified 'Parent's Kiss' for the removal of paediatric nasal foreign bodies. Clin Otolaryngol 2007;32:120-1. [CrossRef]

3. Adedeji TO, Sogebi OA, Bande S. Clinical spectrum of ear, nose and throat foreign bodies in North Western Nigeria. Afr Health Sci 2016;16:292-7. [CrossRef]

4. Craig SS, Cheek JA, Seith RW, West A. Removal of ENT foreign 
bodies in children. Emerg Med Australas 2015;27:145-7.

5. Giourgos G, Matti E, Colombo A, Pagella F. "Hook-scope" technique for endoscopic extraction of nasal foreign bodies. Laryngoscope 2009;119:1203-5. [CrossRef]

6. Alletag MJ, Jacobson D, Santucci K, Riera A. Nasal disc battery removal: a novel technique using a magnetic device. Pediatr Emerg Care 2014;30:488-90. [CrossRef]

7. Kalan A, Tariq M. Foreign bodies in the nasal cavities: a comprehensive review of the aetiology, diagnostic pointers, and therapeutic measures. Postgrad Med J 2000;76:484-7. [CrossRef]

8. Tong MC, Ying SY, van Hasselt CA. Nasal foreign bodies in children. Int J Pediatr Otorhinolaryngol 1996;35:207-11. [CrossRef]

9. Tiago RS, Salgado DC, Corrêa JP, Pio MR, Lambert EE. Foreign body in ear, nose and oropharynx: experience from a tertiary hospital. Braz J Otorhinolaryngol 2006;72:177-81. [CrossRef]

10. Yasny JS. Nasal foreign bodies in children: considerations for the anesthesiologist. Paediatr Anaesth 2011;21:1100-2. [CrossRef]

11. Cetinkaya EA, Arslan IB, Cukurova İ. Nasal foreign bodies in children: Types, locations, complications and removal. Int J Pediatr Otorhinolaryngol 2015;79:1881-5. [CrossRef]

12. Yaroko AA, Baharudin A. Patterns of nasal foreign body in northeast Malaysia: A five-year experience. Eur Ann Otorhinolaryngol Head Neck Dis 2015;132:257-9. [CrossRef]

13. Abou-Elfadl M, Horra A, Abada RL, Mahtar M, Roubal M, Kadiri F. Nasal foreign bodies: Results of a study of 260 cases. Eur Ann Otorhinolaryngol Head Neck Dis 2015;132:343-6. [CrossRef]

14. Endican S, Garap JP, Dubey SP. Ear, nose and throat foreign bodies in Melanesian children: an analysis of 1037 cases. Int J Pediatr Otorhinolaryngol 2006;70:1539-45. [CrossRef]

15. Ogunleye AO, Sogebi OA. Nasal foreign bodies in the African children. Afr J Med Med Sci 2004;33:225-8.

16. Memiş M, İlhan E, Ulucanlı S, Yaman H, Güçlü E. Nasal foreign bodies: an analysis of 130 patients. Kulak Burun Bogaz Ihtis Derg 2015;25:109-12. [CrossRef]

17. Figueiredo RR, Azevedo AA, Kós AO, Tomita S. Complications of ent foreign bodies: a retrospective study. Braz J Otorhinolaryngol 2008;74:7-15. [CrossRef]

18. Chiun KC, Tang IP, Tan TY, Jong DE. Review of ear, nose and throat foreign bodies in Sarawak General Hospital. A five year experience. Med J Malaysia 2012;67:17-20.

19. Claudet I, Salanne S, Debuisson C, Maréchal C, Rekhroukh H, Grouteau E. Nasal foreign body in infants. [Article in French]. Arch Pediatr 2009;16:1245-51. [CrossRef]

20. François M, Hamrioui R, Narcy P. Nasal foreign bodies in children. Eur Arch Otorhinolaryngol 1998;255:132-4. [CrossRef]

21. Shrestha I, Shrestha BL, Amatya RC. Analysis of ear, nose and throat foreign bodies in dhulikhel hospital. Kathmandu Univ Med J (KUMJ) 2012;10:4-8.

22. Leopard DC, Williams RG. Nasal Foreign Bodies: A Sweet Experiment. Clin Otolaryngol 2015;40:420-1. [CrossRef]

23. Treiman R, Rosales N, Kessler B. Characteristics of Print in Books for Preschool Children. Writ Syst Res 2016;8:120-32.

24. ZuckerTA, Justice LM, Piasta SB. Prekindergarten teachers' verbal references to print during classroom-based, large-group shared reading. Lang Speech Hear Serv Sch 2009;40:376-92.

25. Cetin OS, Bay N. Enhancing the early reading skills: Examining the print features of preschool children's book. International Education Studies. 2015;8:113-124.

26. Oh H, Min HJ, Yang HS, Kim KS. Is Radiologic Evaluation Necessary to Find out Foreign Bodies in Nasal Cavity? J Craniofac Surg 2016;27:e62-4. [CrossRef]

27. Tracheobronchial foreign bodies - A seven year review. J Anesth Clin Pharmacol 2007;23:69-74. 